\title{
My Husband Is a Dermatologist
}

I am afraid a creature will rise from the bottom

Of the pond of our country house to devour me.

I find the grassy shore repulsive, and the clotted earth

Unbearable. I find it necessary to rinse the turkey curry

Container out before returning it to the plastic bag,

Out not in the pond water, but in the children's water

Fountain, rinsing the burnished surface of the children's

Water fountain until it is clean, returning the turkey curry

Container to the watery plastic bag, then to the dishwasher,

My clothes to the washing machine, I to the shower, sneakers

To the washing machine, cloth of the laundry hamper

To the washing machine, a sprinkle of Comet

Down the kitchen sink, the residue carried-

And it is carried-somewhere I am not responsible.

I was never, ever his patient. I have had the skin

Of a baby-pacific, luminous-since the day I was born.

Jacketed, he is intent on their celestial backs. If he could,

He would scour the sky itself, and empty it clean of stars. 